\title{
The Effect of Social Class on Agency and Communion: Reconciling Identity-Based and Rank-Based Perspectives
}

Social Psychological and Personality Science 2019, Vol. I0(6) 735-745 (C) The Author(s) 2018 Article reuse guidelines: sagepub.com/journals-permissions DOI: I0.। I77/|9485506/8785।62 journals.sagepub.com/home/spp

@SAGE

\author{
Anna Lisa Aydin', Johannes Ullrich ${ }^{2}$, Birte Siem ${ }^{3}$, \\ Kenneth D. Locke ${ }^{4}$, and Nurit Shnabel ${ }^{5}$
}

\begin{abstract}
How does social class affect people's goals in social interactions? A rank-based perspective suggests actors from higher social classes (compared to lower social classes) have more agentic and less communal goals when interacting with same class or unspecified others. Focusing on targets' social class, an identity-based perspective suggests the reverse: Actors should more strongly endorse communal (agentic) goals toward illegitimately lower class (higher class) compared to illegitimately higher class (lower class) targets, regardless of actors' own social class. Three preregistered experiments $(N=2,023)$ manipulated actor's social class and the nature of the target (illegitimately higher/lower class, same class, unspecified) and measured participants' goals in imagined interactions using the Circumplex Scales of Intergroup Goals. The identity-based perspective received strong support: Across studies, actors expressed stronger agentic (communal) goals toward higher class (lower class) targets. The rank-based perspective received limited support, with relatively low-class (vs. relatively high-class) actors expressing stronger communal goals toward same-class targets.
\end{abstract}

\section{Keywords}

social class, actor, target, agency, communion, Circumplex Scales of Intergroup Goals

In the last decade, social psychologists have become increasingly interested in understanding behavioral styles associated with social class (e.g., Fiske \& Markus, 2012; Kraus, Piff, Mendoza-Denton, Rheinschmidt, \& Keltner, 2012; Stephens, Markus, \& Phillips, 2014). The concept of rank-based social class - the notion that the effect of social class stems from people's perception of their relative ranking in a social hierarchy (Kraus, Tan, \& Tannenbaum, 2013)—has especially advanced this field. This is because experimentally manipulating social class can eliminate confounding factors and isolate the causal role of social class on various psychological outcomes, such as goals people pursue in interactions. These goals, as well as other forms of social cognition and behavior, can be organized along the two fundamental content dimensions of agency and communion (Abele \& Wojciszke, 2014). Agency refers to "the pursuit of independence and autonomy of the individual and aims at control, assertiveness, and self-enhancement," whereas communion refers to "the self as a part of a community and is geared toward closeness, affection, and cooperation" (Grosse Holtforth, Thomas, \& Caspar, 2011, p. 109). While much of the research observed higher communion among lower classes and higher agency among upper classes, other research observed exactly opposing patterns. The present research aimed to reconcile these contradicting patterns by systematically distinguishing between the social class of actor and target within interactions.

The rank-based perspective on social class (Kraus et al., 2012) focuses on predictions for actor class. It accounts for the negative effect of actor class on communion by arguing that because lower class individuals experience more threatening and hostile environments and have less resources and control over outcomes, they must rely more strongly on mutual aid, resulting in communal self-concepts and behaviors. By contrast, upper class individuals have greater control, access to

\footnotetext{
'Institute of Psychology, Social Psychology, Goethe University Frankfurt, Frankfurt, Germany

${ }^{2}$ Department of Psychology, Social Psychology, University of Zurich, Zürich, Switzerland

${ }^{3}$ Institute of Psychology, Social Psychology, FernUniversität in Hagen, Hagen, Germany

${ }^{4}$ Department of Psychology and Communication Studies, University of Idaho, Moscow, ID, USA

${ }^{5}$ School of Psychological Sciences, Tel Aviv University, Tel Aviv, Israel
}

\section{Corresponding Author:}

Anna Lisa Aydin, Institute of Psychology, Social Psychology, Goethe University Frankfurt, Frankfurt 60323, Germany.

Email: aydin@psych.uni-frankfurt.de 
resources, and independence from others, resulting in more individualistic and agentic self-concepts and behaviors (Guinote, Cotzia, Sandhu, \& Siwa, 2015; Kraus \& Mendes, 2014).

Although the rank-based perspective on social class does not explicitly distinguish between interactions with in-group members or "general" interactions in which the target is unspecified, its logic applies to both cases. Specifically, since this perspective highlights the interdependence of lower class individuals within their class as a cause of higher prosociality, it clearly pertains to in-group interactions. Similarly, upper class individuals are presumed to act agentically (e.g., compete over leading positions) with other upper class individuals. These behavioral patterns should also emerge when the social class of the interaction partner is not salient (i.e., in "general" interactions with unspecified others), as it is hypothesized to develop through repeated experiences and become the modus operandi (Kraus et al., 2012). Consistent with the rank-based perspective, various studies - involving situations in which the interaction target's social class was not specified, implicitly resembled one's own social class, or varied unsystematically-found more communal/prosocial behaviors among the lower classes (Dubois, Rucker, \& Galinsky, 2015; Guinote et al., 2015; Kraus \& Callaghan, 2016; Piff, Kraus, Côté, Cheng, \& Keltner, 2010; Stellar, Manzo, Kraus, \& Keltner, 2012). However, studies that at least implicitly took the target's social class into account have found the opposite effect. For instance, Korndörfer, Egloff, and Schmukle (2015), who analyzed survey data in which most targets of respondents' volunteering and charitable donation behavior implicitly belonged to lower social classes, reported more prosociality among the upper classes. Similarly, Liebe, Naumann, and Tutić (2017) showed a positive relationship between occupational status (one aspect of social class) and prosocial behavior. Finally, studies that explicitly varied the target of prosocial behavior found that people's behavior was less communal toward a higher class target but unaffected by participants' own class (van Doesum, Tybur, \& van Lange, 2017).

The main aim of the present research is to reconcile these seemingly contradictory findings by complementing the rank-based perspective with its focus on actor class by an identity-based perspective that takes the target's class into account. Specifically, based on the social identity approach (Tajfel \& Turner, 1986; Turner, Hogg, Oakes, Reicher, \& Wetherell, 1987), we argue that interactions with members from different social classes are likely to increase the salience of categorizations in terms of social class. Consequently, people's goals will shift and align with those of their in-group in the current rank constellation. What motivations, then, guide interactions between people from different social classes? The needs-based model (Nadler \& Shnabel, 2015) posits that in contexts of illegitimate structural inequality, groups of different status experience different threats to their in-group's identities. Whereas members of illegitimately advantaged groups experience threat to - and thus motivation to restore - their in-group's communion (perceived warmth and prosociality), members of illegitimately disadvantaged groups experience threat to - and thus motivation to restore-their in-group's agency (perceived power and capability; Shnabel, Ullrich, Nadler, Dovidio, \& Aydin, 2013; Siem, von Oettingen, Mummendey, \& Nadler, 2013).

Thus, when social class inequality is perceived as illegitimate, the identity-based perspective predicts a positive effect of target class on communion because upper class members should be inclined to restore their in-group's moral image by behaving prosocially (e.g., donating money) toward illegitimately lower class members. It also predicts a negative effect on agency because illegitimately lower class members should be motivated to restore their in-group's agency (e.g., through collective action to improve their access to resources) when interacting with upper class members.

In summary, the rank-based perspective and the identitybased perspective make complementary, not competing, predictions: Whereas the former postulates actor class effects in social interactions with in-group members or unspecified others, the latter postulates target class effects in interactions with out-group members whose relative status is perceived to be illegitimate. While previous studies have provided support for each perspective, different studies have used different samples, manipulations, and measures, and no studies have tested the two perspectives simultaneously. Moreover, in previous research either only actor class was considered or, if both actor and target class were considered, at least one of them was not explicitly manipulated or measured (for an exception, see van Doesum et al., 2017). In fact, no study has simultaneously manipulated actor and target status. The present research is designed to address this gap.

\section{The Present Research}

In the interest of theoretical integration, the present research simultaneously tested the hypotheses from the rank-based perspective and the identity-based perspective. Three preregistered experiments manipulated actors' class (low, high) and the nature of the target (illegitimately higher/lower class outgroup, in-group, unspecified) and measured participants' agentic and communal goals in imagined interactions. Studies 1a and $1 \mathrm{~b}$ (a direct replication) established the ideal conditions for the effects of actor and target class to emerge. Specifically, we assumed the identity-based effects would emerge when highlighting the illegitimacy of class differences and assessing group-level goals (i.e., what goals should we pursue?) in interactions with higher or lower class persons. In contrast, we assumed that the rank-based effects would emerge when assessing individual-level goals (i.e., what goals should $I$ pursue?) in interactions with same-class or unspecified individuals (without mentioning the illegitimacy of class differences).

Because they varied several factors simultaneously — nature of the target (illegitimately higher/lower class out-group, ingroup, unspecified), level of goal pursuit (individual level, group level), illegitimacy of class differences (not mentioned, explicitly mentioned) - Studies $1 \mathrm{a}$ and $1 \mathrm{~b}$ allowed for the predicted opposite effects to emerge but cannot disambiguate the 
exact cause of the differences. To address this limitation, Study 2 tested the predictions of the identity-based perspective against the various possible explanations arising from Studies $1 \mathrm{a}$ and $1 \mathrm{~b}$.

\section{Studies I a and I b}

\section{Method}

The desired sample size of $N=420$ (70 participants per cell) was determined a priori based on power analysis (https://osf. io/u4d6r/). Exclusion of participants (https://osf.io/4zk8t/) and hypothesis testing followed exactly the preregistration (https://osf.io/95pur/).

\section{Participants}

In Study 1a, participants were 515 students from two German universities, most of them from a public distance learning university (396 female, 115 male, 4 other; $M d n_{\text {age }}=30$ ). In Study $1 \mathrm{~b}$, we ran the identical study again on 456 participants recruited by the online research firm workhub (185 female, 270 male, 1 other; $M d n_{\text {age }}=27.50$ ).

\section{Design}

Participants were randomly assigned to the cells of a 2 (actor class [low, high]) $\times 3$ (nature of the target [illegitimately higher/lower class out-group, in-group, unspecified]) design. Note that the design was not strictly orthogonal: In the outgroup target condition, the low (high) actor class manipulation was always paired with an illegitimately higher (lower) class target (see Study 2 for an unconfounded manipulation).

\section{Procedure}

Participants completed a 10-min online survey. First, they provided demographic information including objective social class. Second, we manipulated actor class by asking participants to compare themselves with either extremely low- or high-class targets. Third, we assessed agentic and communal goals toward illegitimately higher/lower class targets, in-group targets, or unspecified others. Finally, we assessed perceived legitimacy of class inequality.

Objective social class. A composite social class measure was computed as the average of standardized income and educational attainment (Kraus \& Keltner, 2009). The correlation between income and education was $r(509)=.15, p=.001$, in Study 1a, and $r(454)=.14, p=.004$, in Study 1b. Participants in both studies reported a median household income of between $€ 25,001$ and $€ 35,000$ and a median educational attainment of a high school diploma (the German "Abitur").

Manipulation of actor class. Actor class (high, low) was manipulated through downward versus upward comparisons (Piff et al., 2010). Participants were presented with a drawing of a ladder with 10 rungs representing people with different levels of education, income, and occupational prestige in German society (with higher numbers reflecting higher classes). Participants assigned to the high (low) actor class condition were asked to compare themselves to people at the very bottom (top) of the ladder and think about the differences between these people and themselves. Then, participants indicated which ladder rung (1-10) they occupied within German society.

Manipulation of nature of the target. We manipulated the nature of the interaction target (illegitimately higher/lower class outgroup, in-group, unspecified) by modifying the instructions participants read before indicating their behavioral goals. Specifically, participants were asked to indicate their goals when interacting with (a) "people who unjustifiably stand at the very bottom/top of the ladder," (b) "people from the same rung as you," or (c) "others in general." Note that only in the outgroup condition targets' position on the social ladder was described as illegitimate. Study 2 drops this restriction.

Agentic and communal goals. To assess agentic and communal goals, we used the Circumplex Scales of Intergroup Goals (CSIG; Locke, 2014), a 32-item measure that assesses a diversity of goals reflecting all possible mixtures of agentic and communal tendencies. The items were translated into German by two independent translators; the final version was backtranslated by a native speaker, reaching very high correspondence with the original version, verified by its author. Table 1 details CSIG items and scale reliabilities; Table 2 summarizes the correlations between agency and communion in each condition.

Participants rated the importance of each goal on 5-point scales ranging from $1=$ not important to $5=$ very important. For the sake of consistency with previous research, we changed the agent in the CSIG items from the group ("we") to the individual ("I") in the in-group and unspecified target conditions (see Study 2 for a separate manipulation of the level of goal pursuit). Table 3 displays dimension reliabilities and descriptive information on the CSIG; for detailed information on how we tested circumplex structure, see https://osf.io/xhau4/.

Perceived legitimacy of social class inequality. Participants indicated to what extent they thought the disparity between people from different ladder rungs was justified, using a single-item scale $(1=$ absolutely unjustified to $5=$ absolutely justified).

\section{Results}

We used R (R Core Team, 2017) for analyses, mainly relying on the packages CircE (Grassi, Luccio, \& Di Blas, 2010), papaya (Aust \& Barth, 2017), and afex (Singmann, Bolker, Westfall, \& Aust, 2017). 
Table I. German and English Version of the Circumplex Scales of Intergroup Goals.

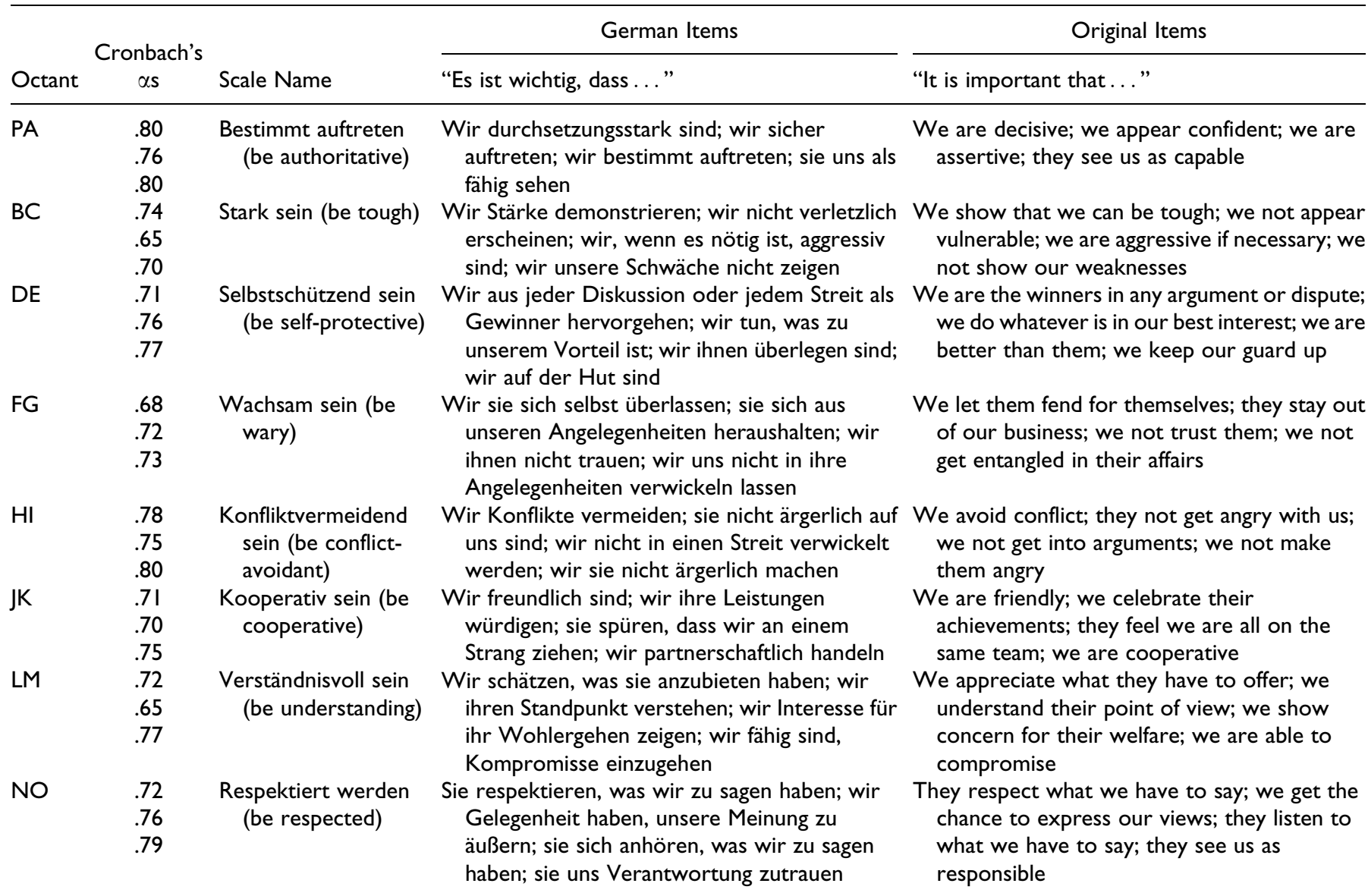

Note. Cronbach's $\alpha$ is shown separately for Studies Ia, Ib, and 2. Respondents' octant scores were combined to yield an overall communion score by subtracting the uncommunal vector from the communal vector $(\mathrm{LM}-\mathrm{DE}+(.707 \times[\mathrm{JK}+\mathrm{NO}-\mathrm{BC}-\mathrm{FG}])$ and an overall agency score by subtracting the unagentic vector from the agentic vector $(P A-\mathrm{HI}+(.707 \times[B C+N O-J K-F G])$; Leary, 1957; Locke, 20II).

Table 2. Correlations Between Agentic and Communal Goals in Studies Ia, Ib, and 2.

\begin{tabular}{lllr}
\hline Condition & $n$ & $r$ & $p$ \\
\hline Study Ia & & & \\
$\quad$ Out-group & 165 & -.58 & $<.001$ \\
In-group & 163 & -.23 & $<.001$ \\
$\quad$ Unspecified & 187 & -.16 & .033 \\
Study Ib & & & \\
$\quad$ Out-group & 177 & -.38 & $<.001$ \\
In-group & 131 & -.11 & .219 \\
Unspecified & 148 & -.13 & .110 \\
Study 2 & 1,052 & -.28 & $<.001$ \\
\hline
\end{tabular}

\section{Manipulation Check}

As intended, in Study 1a, participants in the high actor class condition placed themselves significantly higher on the ladder $(M=6.19, S D=1.64)$ than participants in the low actor class condition, $M=5.66, S D=1.52 ; 95 \%$ confidence interval $(\mathrm{CI})$ of the difference [0.26, 0.80], $t(513)=3.81, p<.001, d=0.34$. In Study 1b, however, participants in the high actor class
Table 3. Dimension Reliabilities and Descriptive Information on the CSIG in Studies Ia, Ib, and 2.

\begin{tabular}{lcccccc}
\hline & \multicolumn{2}{c}{ Agency } & & \multicolumn{2}{c}{ Communion } \\
\cline { 2 - 3 } \cline { 5 - 6 } Study & $\alpha$ & Range & & $\alpha$ & Range \\
\hline Study Ia & .77 & -2.09 to 2.68 & & .88 & & -2.10 to 3.63 \\
Study Ib & .73 & -1.99 to 2.56 & & .87 & & -1.40 to 3.68 \\
Study 2 & .79 & -2.21 to 2.52 & & .90 & & -2.66 to 3.68 \\
\hline
\end{tabular}

Note. Agentic and communal dimension scores theoretically range from -4 to +4 . CSIG $=$ Circumplex Scales of Intergroup Goals.

condition $(M=5.77, S D=1.57)$ placed themselves only marginally above participants in the low actor class condition, $M=$ $5.50, S D=1.57,95 \%$ CI $[-0.02,0.56], t(454)=1.80, p=$ $.072, d=0.17$.

\section{Agentic Goals}

In Study 1a, a 2 (actor class [low, high]) $\times 3$ (nature of the target [illegitimately higher/lower class out-group, in-group, unspecified]) analysis of variance (ANOVA) on agentic goals 


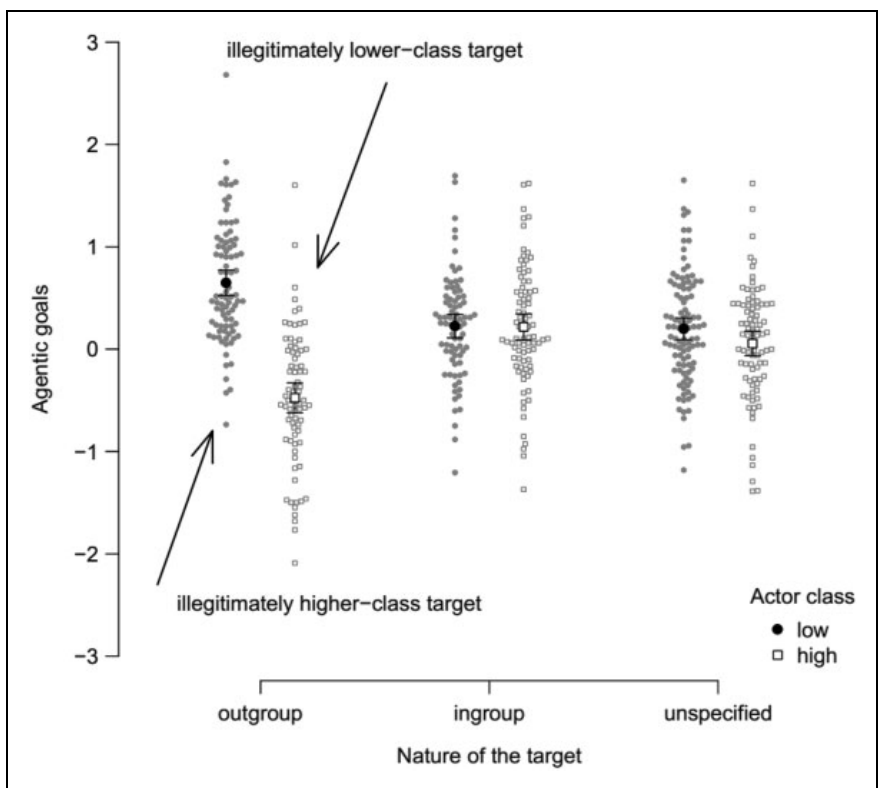

Figure I. Beeswarm plot of agentic goals displayed in the low and high actor class condition in interactions with different targets (Study la). Error bars represent $95 \%$ confidence intervals around the cell means.

revealed a significant main effect of actor class, $F(1,509)=$ $70.69, p<.001, \eta^{2}=.122$, a nonsignificant main effect of nature of the target, $F(2,509)=2.42, p=.090, \eta^{2}=.009$, and a significant two-way interaction, $F(2,509)=47.17, p<.001$, $\eta^{2}=.156$. Figure 1 shows the pattern of results.

As Figure 1 highlights, consistent with the identity-based perspective, participants who imagined interactions with illegitimately higher class targets expressed significantly stronger agentic goals compared to participants who imagined interactions with illegitimately lower class targets (see Table 4 for descriptive and inferential statistics regarding the simple effects from Studies 1a and 1b). Inconsistent with the rankbased perspective, high actor class participants did not show higher agentic goals than low actor class participants in the in-group or unspecified target conditions. Study $1 \mathrm{~b}$ replicated the pattern of significant and nonsignificant effects.

For exploratory purposes, we also examined the effects of objective social class. In Study 1a, one interesting finding emerged from a hierarchical multiple regression analysis. As Table 5 shows, objective social class predicted stronger agency. That is, consistent with the rank-based perspective (Kraus et al., 2012), the higher participants' objective social class, the more pronounced were their agentic goals averaged over all experimental conditions. However, this finding did not replicate in Study $1 b$.

\section{Communal Goals}

A $2 \times 3$ ANOVA on communal goals revealed a significant main effect of social class, $F(1,509)=15.15, p<.001, \eta 2$ $=.029$, which was qualified by a significant two-way interaction, $F(2,509)=33.25, p<.001, \eta 2=.116$. There was no main effect of nature of the target, $F(2,509)=1.72, p=$ $.180, \eta 2=.007$. Figure 2 shows the pattern of results.

Consistent with the identity-based perspective, participants who imagined interactions with illegitimately lower class targets showed significantly higher communal goals compared to participants who imagined interacting with illegitimately higher class targets. This pattern was replicated in Study $1 \mathrm{~b}$ (see Table 4). Consistent with the rank-based perspective, low actor class participants showed significantly higher communal goals than high actor class participants in the ingroup condition. However, this effect was not significant in the unspecified target condition and it did not replicate in Study $1 \mathrm{~b}$ (see Table 4).

In an additional exploratory analysis, a hierarchical multiple regression analysis with communal goals as the dependent variable showed no significant main or moderating effects of objective social class (see Table 5).

\section{Perceived Legitimacy of Social Class Inequality}

Although only the out-group conditions specifically asked participants to imagine interacting with people who unjustifiably stood at the top/bottom of the ladder, with means ranging between $M=2.23$ and $M=2.74$ in Study $1 \mathrm{a}$ and $M=2.45$ and $M=2.82$ in Study $1 \mathrm{~b}$, perceived legitimacy scores were significantly below the midpoint of the 5-point scale in all conditions $(p \mathrm{~s}<.01)$ except for the low actor class/unspecified condition in Study $1 \mathrm{~b}(p=.192)$. Inclusion of this variable did not change the results reported above (see https://osf.io/hdvfz/).

\section{Discussion}

Studies $1 \mathrm{a}$ and $1 \mathrm{~b}$ were designed to provide the ideal conditions for the effects predicted by the rank-based perspective and the identity-based perspective to emerge, and indeed, the overall pattern of results (discussed in the General Discussion) was close to expectations. However, the main limitation of Studies 1a and $1 \mathrm{~b}$ is that effects were confounded for participants imagining interacting with out-group members. Specifically, whereas low actor class participants always imagined interacting with higher class targets, high actor class participants always imagined interacting with lower class targets. Furthermore, participants interacting with out-group members indicated their goal pursuit at the collective level ("we") and were explicitly pointed to the illegitimacy of class differences, whereas participants in the other conditions responded at the individual level ("I") and were not provided with any illegitimacy information. Study 2 tested the predictions of the identity-based perspective with a design avoiding these confounds.

\section{Study 2}

In Study 2, we separately manipulated actor class (low, high), target class (lower, higher), and level of goal pursuit (individual, collective) to conclusively test the prediction that people intend to act more communally toward lower class targets and 
Table 4. Means and Standard Deviations of Agentic and Communal Goals and Effect Sizes of the Social Class Manipulation (Studies Ia and Ib).

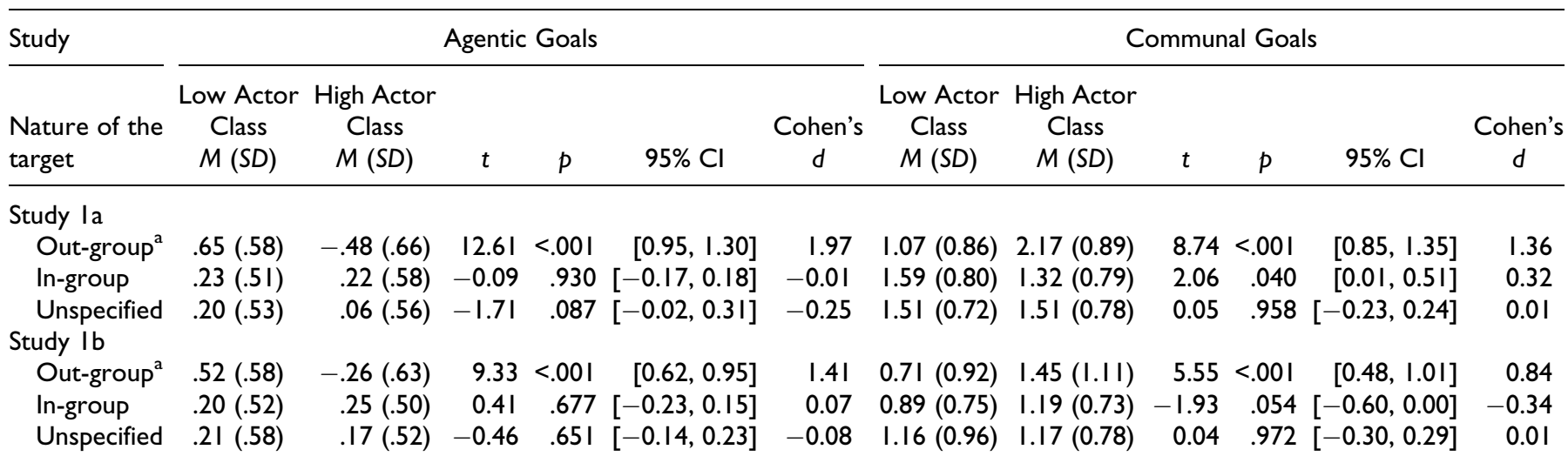

Note. $\mathrm{Cl}=$ confidence interval.

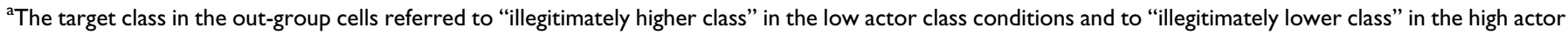
class conditions. In Study Ia, $d f=509$ and in Study Ib $d f=450$.

Table 5. Multiple Regression Analyses Predicting Agentic and Communal Goals From Objective Social Class, Social Class, and Target (Studies la and $\mathrm{Ib}$ ).

\begin{tabular}{|c|c|c|c|c|c|c|c|c|c|c|c|c|}
\hline Predictor & \multicolumn{6}{|c|}{ Study la } & \multicolumn{6}{|c|}{ Study Ib } \\
\hline ocial class (SC) & $-.22 * *$ & .03 & {$[-0.27,-0.17]$} & $.14^{* *}$ & .04 & {$[0.07,0.21]$} & $-.13^{* *}$ & .03 & {$[-0.18,-0.08]$} & $.17^{* *}$ & .04 & {$[0.09,0.26]$} \\
\hline Out-group & -.05 & .04 & {$[-0.12,0.02]$} & .09 & .05 & {$[-0.01,0.19]$} & -.05 & .04 & {$[-0.12,0.02]$} & -.02 & .06 & {$[-0.13,0.10]$} \\
\hline $\mathrm{OSC} \times \mathrm{SC}$ & .05 & .03 & {$[-0.02,0.12]$} & .01 & .05 & {$[-0.08,0.10]$} & -.00 & .04 & {$[-0.07,0.07]$} & $-.0 \mathrm{I}$ & .06 & {$[-0.12,0.11]$} \\
\hline $\mathrm{SC} \times$ Out-Group & $-.34 * *$ & .04 & {$[-0.4 \mathrm{I},-0.27]$} & $.4 I^{* *}$ & .05 & {$[0.3 \mathrm{I}, 0.5 \mathrm{I}]$} & $-.26 * *$ & .04 & {$[-0.33,-0.19]$} & $.20 * *$ & .06 & {$[0.09,0.32]$} \\
\hline $\mathrm{SC} \times \ln$-Group & $.20 * *$ & .04 & {$[0.13,0.27]$} & $-.27 * *$ & .05 & {$[-0.37,-0.17]$} & $.15^{* *}$ & .04 & {$[0.08,0.23]$} & -.03 & .06 & {$[-0.15,0.09]$} \\
\hline OSC $\times$ Out-Group & .03 & .05 & {$[-0.07,0.12]$} & -.00 & .07 & {$[-0.13,0.14]$} & -.01 & .05 & {$[-0.10,0.09]$} & -.02 & .08 & {$[-0.17,0.13]$} \\
\hline OSC $\times$ In-Group & -.03 & .05 & {$[-0.12,0.07]$} & .02 & .07 & {$[-0.11,0.15]$} & -.02 & .05 & {$[-0.13,0.09]$} & -.00 & .09 & {$[-0.17,0.16]$} \\
\hline
\end{tabular}

Note. Social class (reflecting actor class in the in-group and unspecified conditions and target class in the out-group condition) was coded low $=-\mathrm{I}$ and high $=\mathrm{I}$, nature of the target was effect-coded (out-group $=\mathrm{I}$ or 0 , in-group $=\mathrm{I}$ or 0 , unspecified $=-\mathrm{I}$ ). As the inclusion of the three-way interaction (i.e., objective social class, social class, and nature of the target) did not significantly increase the amount of explained variance $\left(\Delta R^{2}=.007, p=.082\right)$, we refer to the model with twoway interactions $\left(\Delta R^{2}=.14 \mathrm{I}, \mathrm{p}<.00 \mathrm{I}\right) . \mathrm{Cl}=$ confidence interval.

$* p<.05 . * * p .01$.

more agentically toward higher class targets. Based on the identity-based perspective, we expected the effect of target class to emerge at all combinations of actor class and level of goal pursuit (although effect sizes might vary). Moreover, Study 2 did not mention the illegitimacy of targets' social class. Should the target class effect be replicated under these conditions, this would suggest that people spontaneously associate the very rich and very poor with illegitimacy. Indeed, in a recent representative survey (GESIS, 2015), only $5 \%$ of the German population agreed that "Social differences in Germany are just."

Finally, an alternative explanation of higher communion toward lower class targets is that people might feel more liking toward lower class than higher class targets, which means that feelings of liking (rather than motives to restore the in-group's communal image as suggested by the identity-based perspective) may explain communal tendencies toward lower class targets. In Study 2, we examined whether-in accord with the identity-based perspective - people would show stronger communal motives toward lower class than higher class targets even when controlling for out-group liking.

\section{Method}

The desired sample size of $N=1,080$ was determined a priori based on power analysis (https://osf.io/u4d6r/). Exclusion of participants (https://osf.io/4zk8t/) and hypothesis testing followed exactly the preregistration (https://osf.io/wgxz6/). 


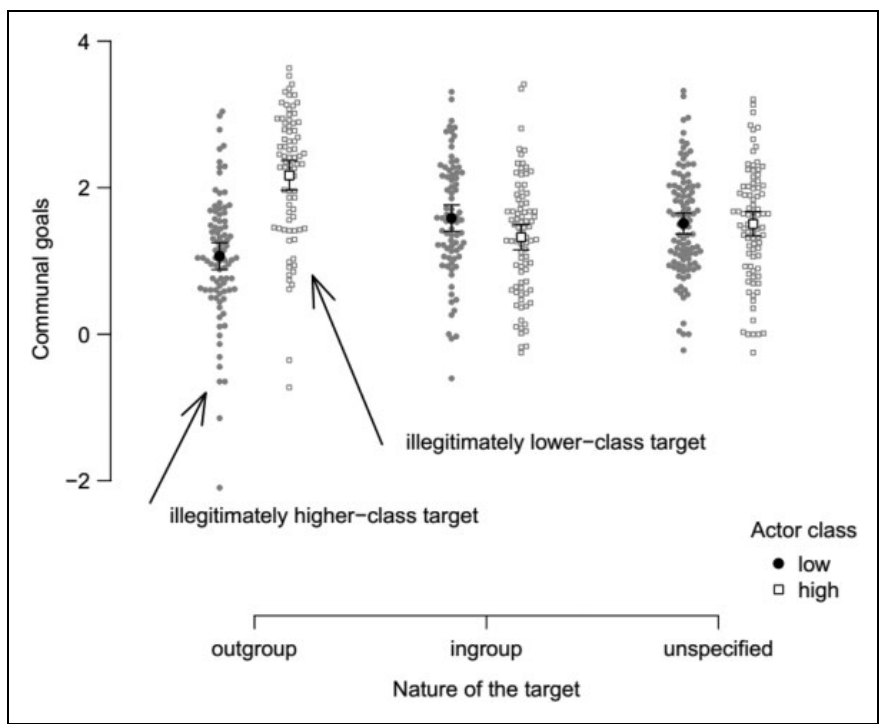

Figure 2. Beeswarm plot of communal goals displayed in the low and high actor class condition in interactions with different targets (Study la).Error bars represent $95 \%$ confidence interval.

\section{Participants}

A sample of 1,052 usable participants (510 female, 540 male, 2 other; $M d n_{\text {age }}=33$ ) was recruited in Germany by the online research firm clickworker. With a median household income of between $€ 25,001$ and $€ 35,000$ and a median educational attainment of a high school diploma, this sample was similar to the samples of Studies $1 \mathrm{a}$ and $1 \mathrm{~b}$ in terms of objective social class. ${ }^{1}$

\section{Design}

Participants were randomly assigned to the cells of the 2 (actor class [low, high] $) \times 2$ (target class [lower, higher] $) \times 2$ (level of goal pursuit [individual, group]) design.

\section{Procedure}

Participants completed a 10-min online survey which contained, in order, demographic questions (including objective social class), the actor class manipulation (low, high), the CSIG (into which was embedded the target class and level of goal pursuit manipulations), and measures of perceived legitimacy of class inequality and liking of the target class. Unless described otherwise below, the measures and manipulations were the same as in Study 1.

\section{Manipulation of Target Class and Level of Goal Pursuit}

Target class and level of goal pursuit were manipulated by changing the instructions for the CSIG items. For example, participants in the individual level condition read: "When $I$ interact with people from the very bottom [top] of the ladder, it is important that...I am friendly," whereas participants in

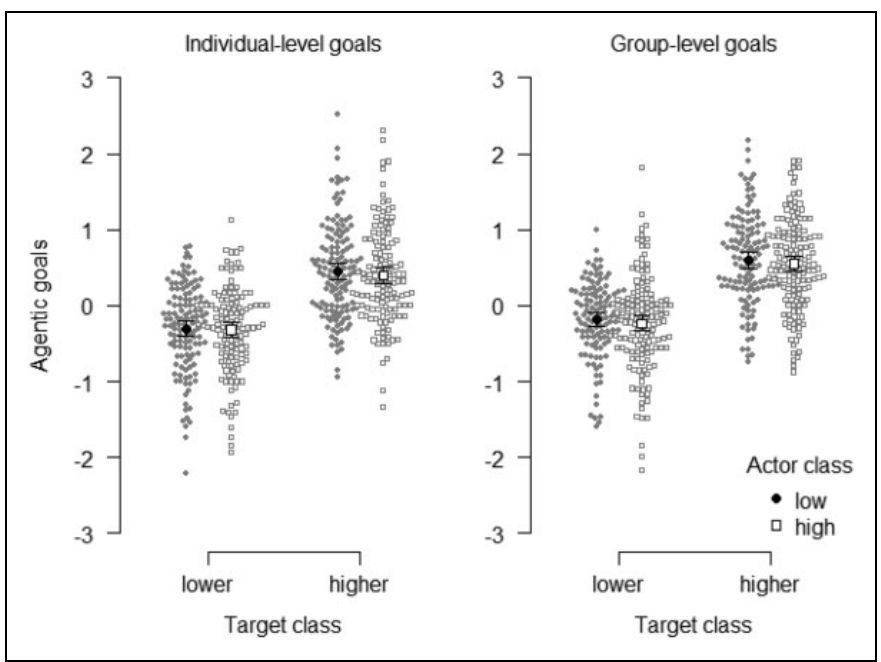

Figure 3. Beeswarm plot of agentic goals as a function of actor class, target class, and level of goal pursuit (Study 2). Error bars represent $95 \%$ confidence interval.

the group level condition read: "When people from my ladder rung interact with people from the very bottom [top] of the ladder, it is important that...we are friendly." Note that (il)legitimacy was not mentioned.

\section{Liking}

We measured target class liking with 1 item ("I like people from the top/bottom of the social ladder"; $1=$ do not agree at all to $5=$ absolutely agree).

\section{Results}

\section{Manipulation Check}

As intended, participants in the high actor class condition placed themselves significantly higher on the ladder $(M=$ $5.63, S D=1.63)$ than participants in the low actor class condition, $M=5.42, S D=1.60 ; 95 \% \mathrm{CI}$ of the difference [0.01, $0.40], t(1,050)=2.06, p=.040, d=0.13$.

As expected, perceived legitimacy scores were below the midpoint of the 5 -point scale in all conditions $(p s<.001)$. Thus, as in Studies 1a and 1b, responses on the CSIG can be interpreted as goals for interactions with illegitimately higher/lower class members. $^{2}$

\section{Agentic Goals}

A 2 (actor class [low, high] $) \times 2($ target class [lower, higher] $) \times$ 2 (level of goal pursuit [individual, group]) ANOVA on agentic goals revealed significant main effects of target class, $F(1,1044)=431.34, p<.001, \eta^{2}=.292$, and goal level, $F(1,1044)=12.12, p=.001, \eta^{2}=.011$. Neither the main effect of actor class, $F(1,1044)=1.36, p=.244, \eta^{2}=.001$, nor any of the two- or three-way interactions were significant. Figure 3 shows the pattern of results. 
Table 6. Means and Standard Deviations of Agentic and Communal Goals and Effect Sizes of the Target Class Manipulation (Study 2).

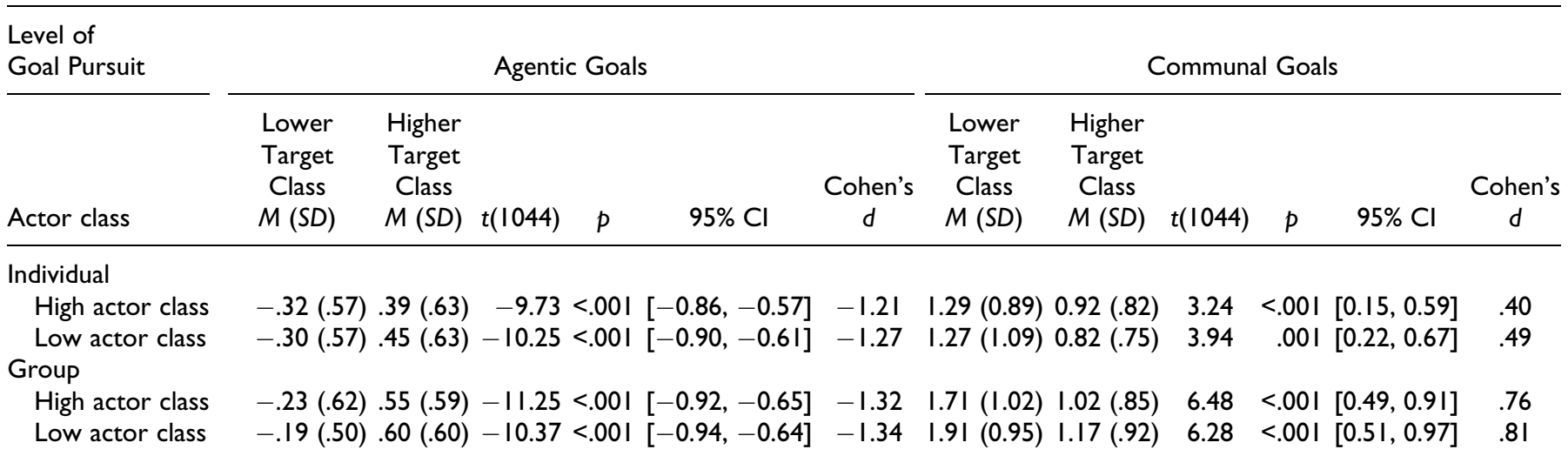

Note. $\mathrm{Cl}=$ confidence interval.

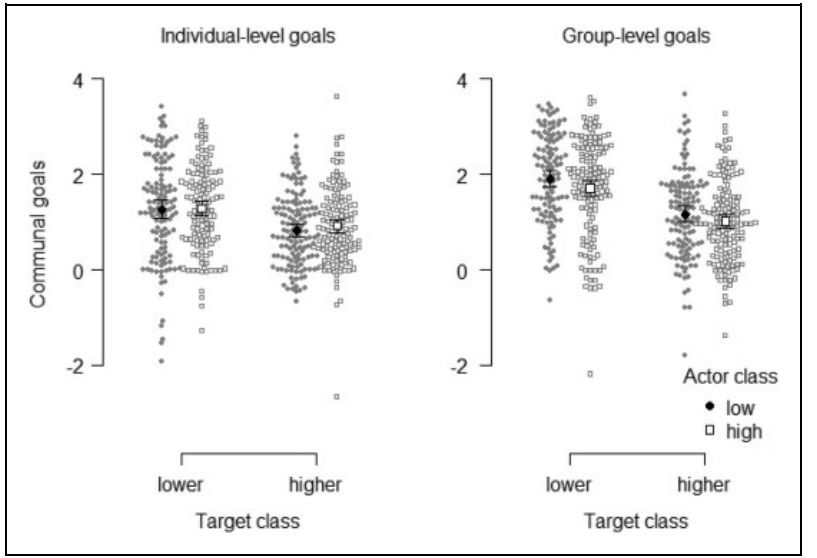

Figure 4. Beeswarm plot of communal goals as a function of actor class, target class, and level of goal pursuit (Study 2). Error bars represent $95 \%$ confidence interval.

Consistent with the identity-based perspective, the target class main effect indicates that participants who imagined an interaction with higher class targets showed higher agentic goals compared to participants who imagined an interaction with lower class targets. This effect persisted irrespective of actor class and level of goal pursuit (see Table 6 for descriptive and inferential statistics regarding the simple effects of Study 2).

The main effect of goal level indicates that agentic goals were somewhat more pronounced when pursued on the group (vs. the individual) level.

\section{Communal Goals}

A $2 \times 2 \times 2$ ANOVA on communal goals revealed the expected main effect of target class, $F(1,1044)=99.01$, $p<.001, \eta^{2}=.087$, which was qualified by a significant target class $\times$ goal level interaction, $F(1,1044)=7.59, p=.006$, $\eta^{2}=.007$, such that the predicted effect of target class was stronger when participants indicated their collective rather than individual goals. Figure 4 depicts the pattern of results.

This ordinal interaction is consistent with our hypothesis that the simple effect of target class on communal goals would be negative at all levels of the other factors (i.e., actor class and level of goal pursuit): Participants showed higher communal goals toward lower class targets than toward higher class targets in all four cells (see Table 6).

As indicated by a significant effect of goal level, $F(1,1044)=44.28, p<.001, \eta^{2}=.041$, similar to agentic goals, communal goals were more pronounced when pursued on the group (vs. the individual) level across the actor and target class conditions.

Although the main effect of actor class was not significant, $F(1,1044)=0.97, p=.324, \eta^{2}=.001$, an unexpected Actor Class $\times$ Goal-Level interaction emerged, $F(1,1044)=4.48$, $p=.035, \eta^{2}=.004$, such that the effect of actor class on communal goals was significant when pursued on the group level, $t(1,044)=2.20, p=.028, d=0.50$, but not on the individual level, $t(1,044)=-0.80, p=.426, d=-0.28$. Interestingly, the direction of this effect is consistent with predictions derived from the rank-based perspective: Across target class conditions, communal goals were stronger among low actor class than high actor class participants.

\section{Controlling for Liking}

Finally, we tested the alternative explanation that the target class effect might be due to greater liking of low-class targets. Indeed, participants liked people at the bottom $(M=3.23$, $S D=0.75)$ more than people at the top $(M=2.98, S D=$ $0.75)$ of the ladder, $t(1048.12)=5.48, p<.001, d=0.34$. However, after including liking as a covariate, the effects of target class on communal and agentic goals remained significant and their effect sizes were reduced only minimally (by $\eta^{2}=.02$ for both communal and agentic goals). This finding strengthens the identity-based theorizing that increased communal goals toward lower class targets (vs. higher class 
targets) reflect participants' motivation to restore their threatened moral-social identity.

\section{Discussion}

The results of Study 2 ruled out several alternative explanations, suggesting that the results predicted by the identitybased perspective are not driven by confounds existing in the designs of Studies 1a and 1b.

Specifically, in a context of class inequality (generally perceived as illegitimate), participants endorsed agentic goals toward higher class targets and communal goals toward lower class targets, irrespective of their own social class (i.e., actor class) and irrespective of level of goal pursuit (although the effect of target class on communion was stronger when participants indicated their collective rather than individual goals). Furthermore, this pattern of results remained the same after controlling for liking, which corroborates the assumption that the pursuit of communal and agentic intergroup goals is driven by advantaged or disadvantaged group members' needs to restore their own positive identities (rather than solely by how they feel about the out-group; Nadler \& Shnabel, 2015).

Although Study 2 focused on out-group interactions and was not designed to test predictions of the rank-based perspective, we obtained an unpredicted effect of actor class on communion that is broadly consistent with the results of Study 1a. Specifically, low-class participants pursued higher communal goals than high-class participants, irrespective of target class, though this was only true for group-level goals.

\section{General Discussion}

The recent surge of social psychological research on social class, heavily informed by the rank-based perspective (e.g., Kraus et al., 2012), suggests that differences in behavioral styles of those at the top (more independence, risk taking, agency) and the bottom of the hierarchy (more interdependence, deference to authority, communion) may contribute to the maintenance of social inequality. However, as Markus (2017) notes in her recent commentary: "These behavioral tendencies are not inherent; they are socially afforded and promoted and can change with different social circumstances" (p. 214).

By complementing the rank-based perspective with an identity-based perspective (e.g., Shnabel \& Ullrich, 2013), the present research contributes to a better understanding of just what these circumstances may be that reverse the pattern of higher agency and lower communion of higher class individuals. According to the identity-based perspective, when class differences are perceived to be illegitimate, people will pursue agentic goals in interactions with higher class members and communal goals in interactions with lower class members. Put differently, even more than the actor's class, the target's class heavily influences behavioral expressions of agency and communion.
Overall, results of the present research strongly support the identity-based perspective but only partially support the rank-based perspective. Whereas people reliably and strongly endorsed agentic goals toward illegitimately higher class targets and communal goals toward illegitimately lower class targets, their own class had less consistent effects. In fact, the only effects we observed were that low-class actors more strongly endorsed communal goals in interactions with same-class targets than high-class actors, as well as a positive main effect of objective social class on agentic goals. These effects were obtained in Study 1a but were not replicated in Study 1b. Finally, in Study 2, we obtained a negative effect of actor class on communal goals pursued on the group level, which may be viewed as consistent with the rank-based perspective (albeit this perspective makes explicit predictions about individuallevel rather than group-level goals).

One potential reason for the rather limited support for the rank-based perspective is that it is easier to manipulate target class than to manipulate actor class. It is important to point out that the relative rank manipulation cannot be understood as an operationalization of social class as a sociocultural concept (Stephens \& Townsend, 2013). Rather, the use of this surrogate is a compromise, the value of which is that it allows experimental examination of the causal effects of social class. However, we also failed to find consistent correlational evidence for the rank-based perspective using objective social class (a composite measure of income and educational attainment). It remains a challenging task to develop other operationalizations to extract the effect of actor class while maintaining both construct validity (as when using objective social class measures) and internal validity (as when using the rank-based manipulation).

To summarize, our findings suggest that the behavioral styles of low- and high-class members described in current literature may not be so deeply ingrained. Rather, the emergence of agentic and communal motives may depend on the social class of both the actor and the other partner(s) to the interaction. This insight is a starting point for identity-based and rank-based perspectives to mutually enrich each other regarding the fundamental question of how social class influences social goals and behavior, with critical implications for understanding possible routes for social change.

\section{Declaration of Conflicting Interests}

The author(s) declared no potential conflicts of interest with respect to the research, authorship, and/or publication of this article.

\section{Funding}

The author(s) disclosed receipt of the following financial support for the research, authorship, and/or publication of this article: This work was supported by Deutsche Forschungsgemeinschaft (RO 4826/1-1) and German-Israeli Foundation for Scientific Research and Development (G-1119). 


\section{Notes}

1. Because Study 2 was designed to complement the experimental design of Study 1 with regard to out-group interactions, we did not predict an effect of objective social class, which is hypothesized to affect behavioral goals in in-group or unspecified interactions. Running exploratory multiple regression analyses with actor class, target class, goal level, and objective class as independent variables revealed a significant positive main effect of objective social class on communal goals $(b=.08, S E=.04, p=.033)$ and no effect on agentic goals. We refrain from interpreting this finding for the above reasons.

2. Consistent with the notion of insecure status relations (Tajfel \& Turner, 1986), exploratory moderator analyses found that the identity-based effects of target class on agency and communion were stronger, the lower the perceived legitimacy and stability of class differences, and the lower the perceived permeability of class boundaries (see analysis code https://osf.io/nztxd/).

\section{References}

Abele, A. E., \& Wojciszke, B. (2014). Communal and agentic content in social cognition: A dual perspective model. In J. M. Olson \& M. P. Zanna (Eds.), Advances in Experimental Social Psychology (Vol. 50, pp. 195-255). San Diego, CA: Academic.

Aust, F., \& Barth, M. (2017). Papaja: Create APA manuscripts with $R$ Markdown. R package version 0.1.0.9492. Retrieved from https:// github.com/crsh/papaja

Dubois, D., Rucker, D. D., \& Galinsky, A. D. (2015). Social class, power, and selfishness: When and why upper and lower class individuals behave unethically. Journal of Personality and Social Psychology, 108, 436-449. doi:10.1037/pspi0000008

Fiske, S. T., \& Markus, H. R. (2012). Facing social class. How societal rank influences interaction. New York, NY: Russell Sage.

GESIS - Leibniz Institute for the Social Sciences (2015). ALLBUS/ GGSS 2014 (Allgemeine Bevölkerungsumfrage der Sozialwissenschaften/German General Social Survey 2014). GESIS Data Archive, Cologne. ZA5240 Data file Version 2.1.0. http://dx.doi. org/10.4232/1.12288

Grassi, M., Luccio, R., \& Di Blas, L. (2010). CircE: An R implementation of Browne's circular stochastic process model. Behavior Research Methods, 42, 55-73. doi:10.3758/BRM.42.1.55

Grosse Holtforth, M., Thomas, A., \& Caspar, F. (2011). Interpersonal motivation. In L. M. Horowitz \& S. Strack (Eds.), Handbook of interpersonal psychology (pp. 107-122). New York, NY: Wiley.

Guinote, A., Cotzia, I., Sandhu, S., \& Siwa, P. (2015). Social status modulates prosocial behavior and egalitarianism in preschool children and adults. Proceedings of the National Academy of Sciences, 112, 731-736. doi:10.1073/pnas.1414550112

Korndörfer, M., Egloff, B., \& Schmukle, S. C. (2015). A large scale test of the effect of social class on prosocial behavior. PLOS ONE, 10, e0133193. doi:10.1371/journal.pone.0133193

Kraus, M. W., \& Callaghan, B. (2016). Social class and prosocial behavior: The moderating role of public versus private contexts.
Social Psychological and Personality Science, 7, 769-777. doi:10.1177/1948550616659120

Kraus, M. W., \& Keltner, D. (2009). Signs of socioeconomic status: A thin-slicing approach. Psychological Science, 20, 99-106. doi:10. 1111/j.1467-9280.2008.02251.x

Kraus, M. W., \& Mendes, W. B. (2014). Sartorial symbols of social class elicit class-consistent behavioral and physiological responses: A dyadic approach. Journal of Experimental Psychology: General, 143, 2330-2340. doi:10.1037/xge0000023

Kraus, M. W., Piff, P. K., Mendoza-Denton, R., Rheinschmidt, M. L., \& Keltner, D. (2012). Social class, solipsism, and contextualism: How the rich are different from the poor. Psychological Review, 119, 546-572. doi:10.1037/a0028756

Kraus, M. W., Tan, J. J., \& Tannenbaum, M. B. (2013). The social ladder: A rank-based perspective on social class. Psychological Inquiry, 24, 81-96. doi:10.1080/1047840X.2013.778803

Leary, T. (1957). Interpersonal diagnosis of personality. New York, NY: Ronald. doi:10.1080/08853126.1957.10380790

Liebe, U., Naumann, E., \& Tutić, A. (2017). Sozialer status und prosoziales handeln: Ein quasi-Experiment im krankenhaus [In German] [Social status and prosocial behavior: A quasiexperiment in the hospital]. Kölner Zeitschrift für Soziologie und Sozialpsychologie, 69, 109-129. doi:10.1007/s11577-016-0399-9

Locke, K. D. (2011). Circumplex measures of interpersonal constructs. In L.M. Horowitz \& S. Strack (Eds.), Handbook of Interpersonal psychology: Theory, Research, Assessment and Therapeutic Interventions (pp. 313-342). New Jersey, NJ: John Wiley.

Locke, K. D. (2014). Circumplex scales of intergroup goals: An interpersonal circle model of goals for interactions between groups. Personality and Social Psychology Bulletin, 40, 433-449. doi:10.1177/0146167213514280

Markus, H. R. (2017). In this together: Doing and undoing inequality and social class divides. Journal of Social Issues, 73, 211-221. doi:10.1111/josi.12212

Nadler, A., \& Shnabel, N. (2015). Intergroup reconciliation: Instrumental and socio-emotional processes and the need based model. European Review of Social Psychology, 26, 93-125. doi:10.1080/ 10463283.2015.1106712

Piff, P. K., Kraus, M. W., Côté, S., Cheng, B. H., \& Keltner, D. (2010). Having less, giving more: The influence of social class on prosocial behavior. Journal of Personality and Social Psychology, 99, 771-784. doi:10.1037/a0020092

R Core Team. (2017). R: A language and environment for statistical computing. R Foundation for Statistical Computing, Vienna, Austria. Retrieved from https://www.R-project.org/

Shnabel, N., \& Ullrich, J. (2013). Increasing intergroup cooperation toward social change by restoring advantaged and disadvantaged groups' positive identities. Journal of Social and Political Psychology, 1, 216-238. doi:10.5964/jspp.v1i1.187

Shnabel, N., Ullrich, J., Nadler, A., Dovidio, J. F., \& Aydin, A. L. (2013). Warm or competent? Improving intergroup relations by addressing threatened identities of advantaged and disadvantaged groups. European Journal of Social Psychology, 43, 482-492. doi:10.1002/ejsp.1975 
Siem, B., von Oettingen, M., Mummendey, A., \& Nadler, A. (2013). When status differences are illegitimate, groups' needs diverge: Testing the needs-based model of reconciliation in contexts of status inequality. European Journal of Social Psychology, 43, 137-148. doi:10.1002/ejsp.1929

Singmann, H., Bolker, B., Westfall, J., \& Aust, F. (2017). Afex: Analysis of factorial experiments. R package version 0.18-0. Retrieved from https://CRAN.R-project.org/package $=$ afex

Stellar, J. E., Manzo, V. M., Kraus, M.W., \& Keltner, D. (2012). Class and compassion: Socioeconomic factors predict responses to suffering. Emotion, 12, 449-459. doi:10.1037/a0026508

Stephens, N. M., Markus, H. R., \& Phillips, L. T. (2014). Social class culture cycles: How three gateway contexts shape selves and fuel inequality. Annual Review of Psychology, 65, 611-634. doi:10. 1146/annurev-psych-010213-115143

Stephens, N. M., \& Townsend, S. S. M. (2013). Rank is not enough: Why we need a sociocultural perspective to understand social class. Psychological Inquiry, 24, 126-130. doi:10.1080/ 1047840X.2013.795099

Tajfel, H., \& Turner, J. C. (1986). The social identity theory of intergroup behavior. In S. Worchel \& W. G. Austin (Eds.), Psychology of intergroup relations (pp. 7-24). Chicago, IL: NelsonHall.

Turner, J. C., Hogg, M. A., Oakes, P. J., Reicher, S. D., \& Wetherell, M. S. (1987). Rediscovering the social group: A selfcategorization theory. Oxford, England: Basil Blackwell.

van Doesum, N. J., Tybur, J. M., \& van Lange, P. A. (2017). Class impressions: Higher social class elicits lower prosociality. Journal of Experimental Social Psychology, 68, 11-20. doi:10.1016/j.jesp. 2016.06.001

\section{Author Biographies}

Anna Lisa Aydin is a lecturer and research assistant at Goethe University. In her research, she focuses on intergroup relations, conflict, and reconciliation processes.

Johannes Ullrich is a social psychologist mainly interested in intergroup relations, social cognition, and research methods.

Birte Siem is a lecturer in social psychology and community psychology at the University of Hagen. Her research interests include prosocial behavior, intergroup relations, and social inequality.

Kenneth D. Locke is a professor of psychology and past-president of the Society for Interpersonal Theory and Research. His scholarly interests include social comparison, circumplex models of social relations, and modeling attitudinal and behavioral consistency within and between individuals.

Nurit Shnabel is a senior lecturer of social psychology at Tel Aviv university. Her scholarly interests include interpersonal and intergroup reconciliation processes, which she studies primarily from the perspective of the needs-based model, as well as intergroup relations with a particular interest on gender roles and the social psychological mechanisms that preserve them.

Handling Editor: Joseph Simmons 